\title{
Cerámica nazarí tardía y cristiana de "El Castillejo"(Los Guájares, Granada).
}

Alberto García Porras.

\section{INTRODUCCIÓN.}

El presente artículo tiene como objeto el estudio de un lote cerámico procedente del yacimiento medieval de El Castillejo, término municipal de Los Guájares, Granada. El citado yacimiento se encuentra sobre una escarpada roca caliza en la margen derecha del río de la Toba. A lo largo de cuatro campañas (1985, 1986, 1987 y 1989) se exhumó la mayor parte de las estructuras que lo componen y se extrajo una importante cantidad de material cerámico que desde un principio prometía aportar importantes novedades que contribuirían a completar las informaciones que sobre la cerámica nazarí se tenía hasta el momento. Los resultados de los primeros análisis de este conjunto cerámico aportaron resultados tan interesantes como se esperaba; se trataba de un ajuar cerámico muy homogéneo, fechable en un momento situado entre finales del siglo XIII y principios del siglo XIV, es decir, una cerámica que se consideró como "prototipos de piezas nasríes tardías" (CRESSIER, RIERA, RO-SELLÓ, 1992: p.8.).

Tras un examen más detallado de todos los fragmentos hallados en este yacimiento, pudimos comprobar que junto al mayoritario grupo de cerámicas "protonazaríes", se podía encontrar un pequeño número de piezas no atribuibles a este período, sino a uno posterior!. Al tratarse de un conjunto cerámi- co muy homogéneo, como ya se ha señalado, estos fragmentos quedaban perfectamente aislados en el global cerámico del Castillejo. Este pequeño grupo de cerámicas, que hemos considerado nazaríes-tardías o en algunos casos como cristianas del XVI, es el que centra el interés de este trabajo.

Cuando comenzamos a estudiar este pequeño grupo de cerámicas, topamos inmediatamente con un importante obstáculo: la escasez bibliográfica existente a este respecto. En el caso de la cerámica nazarí contábamos con algunas publicaciones. Por lo que se refiere a la cerámica cristiana del XVI, al margen de los estudios relativos al ciclo Paterna-Manises, pocos eran los trabajos dedicados a esta cerámica, sobre todo la adscribible a los siglos $X V$ $X V I$. El problema era aún mayor si lo que intentábamos era buscar puntos de referencia más cercanos geográficamente a nuestro entorno; en este caso eran contados los trabajos cuyas páginas incluyeran ejemplos cerámicos de este tipo.

Esto nos animó aún más a publicar unos materiales a nuestro juicio muy interesantes, pues nos acercaban a una etapa de vital importancia dentro de la evolución histórica de estas regiones de Andalucía Oriental: el tránsito de una sociedad islámica a una sociedad cristiana con todos los problemas que toda sociedad en transición presenta. Es desde

I Extremo que ya se apuntaba en el citado trabajo como ocupaciones puntuales y/o intermitentes tardías. (CRESSIER, RIERA, ROSELLÓ, 1992, p. 7.) 
este punto de vista desde el que pretendemos enfocar el presente trabajo, para lo cual nos parece esencial insertar el yacimiento del Castillejo dentro de todo el conjunto del poblamiento medieval de la región en la que se encuentra, los cambios que esta zona experimenta con la conquista castellana, y de qué modo éstos han influido en la producción cerámica.

El interés pues es doble: por una parte intentar dar una explicación completa del asentamiento, no sólo en su etapa de mayor ocupación, sino también de las reocupaciones de carácter temporal que tuvieron lugar posteriormente, y las razones de éstas. Por otro lado, con la publicación de estos materiales esperamos contribuir a reforzar una línea de investigación cuyo desarrollo no ha tenido hasta el momento la importancia que le correspondería a tenor de los hallazgos de materiales similares en esta zona, que los sitúan cuantitativa y cualitativamente en un nivel muy superior.

\section{EL CASTILLEJO: CONJUNTO RURAL DE LA COSTA GRANADINA.}

\section{Poblamiento medieval de la Costa.}

El yacimiento en cuestión se sitúa en una empinada loma en la margen derecha del río de la Toba, dominando el valle, en el actual término municipal de Los Guájares². En época medieval esta zona formaba parte de una unidad más extensa aunque manteniendo respecto a ésta su propia identidad.

Nos referiremos a la Costa Granadina en relación a la franja que abarca desde la ensenada de la Herradura por el $O$, hasta la rábita de Albuñol por el $E$, aunque también la integran zonas interiores como las vertebradas alrededor del río Verde, la del tramo final del Guadalfeo y su vega, y el área de la Alpujarra costera con las tacas de Sāḥl y Suhayl (MALPI-

\footnotetext{
2 M.T.N.E., E. I/25.000, hoja I04I-IV(Los Guájares) ${ }^{44730 / 40770 I . ~}$

3 La Bernardilla, Guájar Fondón, Guájar Faragüit y Guájar Alto.
}

CA, 1986). Aunque todas mantienen unos rasgos comunes que las permiten integrarse dentro de una misma unidad, sería demasiado arriesgado afirmar que no poseen estructuras de poblamiento diversas y aún más, rasgos individualizadores. En este sentido podríamos hablar de cuatro zonas dentro de la Costa granadina (MALPICA, 1989):

- Almuñécar y su distrito (MALPICA, RODRIGUEZ, 1982: pp. 7I-89), que se articulan primordialmente en torno a los ríos Verde y Seco, con un área próxima en el río Jete. Compuesto por una importante madīna amurallada con dos arrabales además de una nutrida red de alquerías.

- Salobreña (MALPICA, I990: pp. 99- I29), vertebrada alrededor del curso bajo del río Guadalfeo, puede aún dividirse en varias zonas. La vega, con una importante madīna, como Salobreña (propiedad de la hacienda real). Motril, no documentada antes del siglo XIV, además de Molvizar y Lobres. En una zona situada más al interior, las alquerías de Vélez Benaudalla en la margen izquierda del Guadalfeo, y en la derecha las situadas en el Valle de la Toba ${ }^{3}$.

-La țāo de Suhayl (MALPICA, 199I) organizada en torno a Sierra Lújar y su caída al mar, su poblamiento es eminentemente rural y dedicado casi con exclusividad a tareas agrícolas y pesqueras en su estrecha franja litoral.

-La țāa a de Sāḥyl, de características similares a la anterior, su vida giraba en torno a varios subconjuntos: el de Torvizcón, cuyas aguas vierten al Guadalfeo alpujarreño; el de Albuñol en el Sur, y en la zona más oriental el que se encuentra agrupado en torno a Murtas.

Toda esta región mantenía unos rasgos comunes: la vida económica de esta zona reposaba en una agricultura intensiva y de regadío, en la que los sistemas hidráulicos (derivaciones, acequias, qanāt, acueductos, 
etc...) y el acondicionamiento del terreno para un mejor aprovechamiento de los recursos hídricos (redes hidráulicas y áreas de abancalamiento) juegan un papel primordial. Sobre estas bases, se levantaba el edificio del poblamiento, resultando el núcleo básico de éste la alquería, siempre bien provista de agua. En ella se concentraban los propietarios de las parcelas cercanas, al menos hasta finales de la Edad Media. (MALPICA, 1989: p. 176). Junto a la alquería, y en un nivel superior se halla la madīna, que "marcaba sus ritmos de expansión o de crisis sobre las tierras más próximas" (MALPICA, 1989: p. 176). Recintos amurallados en algunas ocasiones a los que se unían arrabales, la actividad comercial de sus zocos y la de comerciantes extranjeros en algunas ocasiones, las separaban de sus alquerías más cercanas.

El valle del río de la Toba quedaría pues dentro de la segunda estructura de poblamiento citada: la de Salobreña, ocupando un lugar periférico respecto a ésta al ser un valle transversal a uno de los ejes principales de la Costa. El río de la Toba, afluente del Guadalfeo, está bordeado por varios yacimientos medievales a los que riega con sus aguas (CRESSIER, MALPICA, ROSELLÓ 1987 : pp. 150- 160); en la actualidad algunos de ellos se encuentran en áreas habitadas, mientras otros son despoblados que conservan restos de construcciones. De la desembocadura al curso alto de este río encontramos la Bernardilla, actualmente un cortijo, que se asienta en la desembocadura del río, lugar donde su cauce se ensancha considerablemente ${ }^{4}$. El Minchar ${ }^{5}$ donde se hallaron restos de sigillata que indicaban la existencia de un yacimiento romano datado entre los siglos I a.C a III-IV d.C6; en época medieval está documentado como un pago de regadío, lo cual unido al topónimo "minchar", que puede proceder de una transformación del árabe maŷ- šar -cortijo-, nos hace pensar que se trataría de una zona de cultivo intensivo con alguna estructura de habitación. Los pueblos de Guájar Fondón y Guájar Faragüit, en el curso medio del río; Guájar la Viejaª situada en el antiguo camino que unía en época nazarí la Costa con Granada, y donde aún se pueden observar restos constructivos y cerámicos similares a los aparecidos en el Castillejo (siglos XIII-XIV); Guájar Alto, situado en el curso alto del río de la Toba; y Cerro Fuerte ${ }^{8}$, en las proximidades de este último, en una roca elevada sobre el río a 1.053 metros de altitud. En su cima, una pequeña meseta, aún se observan restos de muros y cerámicas que testimonian el momento de su ocupación. Por último, encontramos el Castillejo, del que nos ocuparemos en adelante.

\section{Estructuras castellanas sobre el pobla- miento de la Costa.}

La conquista castellana de estas tierras trajo consigo importantes transformaciones socio-económicas que se dejaron sentir sobre la estructura de poblamiento. La implantación se canalizó básicamente por medio de las concesiones territoriales llevadas a cabo por los Reyes Católicos y por la repoblación de las tierras conquistadas. Estos mecanismos de poder se proyectaron en el territorio desde los núcleos urbanos y las fortificaciones conservadas de épocas anteriores, lugares donde sólo vivían castellanos (MALPICA, 1989: p. |81). Todo esto produjo una serie de rupturas territoriales, resultado de la unión de dos dinámicas distintas de poblamiento: por un lado los castellanos, que habían recibido importantes lotes de tierra, comenzaron a no cumplir las duras obligaciones colectivas heredadas del sistema de organización del poblamiento islámico (reparto de riegos, etc...) y a sustituir los cultivos islá-

\footnotetext{
4 M.T.N.E, E. I/25.000, hoja I055-II. (Molvizar). ${ }^{45180 / 407460 .}$

5 M.T.N.E., E. I/25.000, hoja I04I-IV, (Los Guájares), ${ }^{4} 4837 / 407732$.

6 Información ofrecida por los profesores Mercedes Roca y Nicolás Marín, de la Universidad de Granada.

7 M.T.N.E., E. 125.000, hoja I04I-IV, (Los Guájares), ${ }^{44420 / 408033 . ~}$

8 M.T.N.E., E. I/25.000, Hoja I04I-IV (Los Guájares), ${ }^{4} 4205 /{ }^{40} 8013$
} 
micos intensivos por otros mejor conocidos por ellos y mayormente demandados por los nuevos pobladores, convirtiendo muchas tierras productivas agrícolamente en dehesas para mantener el sistema ganadero castellano. Por otro lado los mudéjares que se mantuvieron en sus tierras (pues fueron muchos los que decidieron marcharse a la otra orilla del Mediterráneo aprovechando las facilidades que leyes y autoridades castellanas les concedían para este fin), debieron soportar una mayor carga impositiva (MALPICA, 1989: p. 184). Resultado de estas dos líneas convergentes, fueron los importantes brotes de violencia que sufrieron las tierras de la Costa a principios del siglo $\mathrm{XVl}$; las armas no hicieron más que empeorar, y aún más, desarrollar la línea tendencial trazada desde la conquista. Ahora se convierten en masivas las huidas, quedando incluso algunas alquerías completamente deshabitadas a pesar de los impedimentos, incluso militares, que las autoridades castellanas, en vista de la importante disminución en la recaudación impositiva que ello suponía, habían impuesto. Con todo ello, sólo se favorecía la concentración de tierras en manos de los señores castellanos, que cada vez apostaban más fuerte por los cultivos extensivos más rentables para ellos y por el ganado.

El valle del río Toba también sufrió los combates entre las dos partes enfrentadas; en particular esta dinámica se nos presenta con la rebelión morisca acaecida en esta zona en la segunda mitad del siglo XVI. En este caso, el cronista Luis del Mármol Carvajal nos describe cómo los moriscos de los Guájares, Valle de Lecrín e incluso de las tierras de Alhama, resistieron a las fuerzas castellanas en el Cerro del Fuerte (MÁRMOL, 1946: pp. 246-247).

\section{EL CASTILLEJO: ESTRUCTURA, ELEMENTOS Y ORGANIZACIÓN:}

Lo que conocemos como "El Castillejo" de los Guájares, se sitúa en la cima de una roca a unos 400 metros de altitud sobre el nivel del mar. El asentamiento aparece rode- ado por una estructura amurallada defensiva con tres pequeñas torres cuadradas, que define un espacio oval con una orientación W-E y de unas dimensiones de $|20 \times| 30$ metros. La primitiva entrada al recinto, situada en la zona occidental, estaba constituida por una puerta en recodo, y asociada a ella se conservan aún los vestigios de una estructura rectangular utilizada como baluarte defensivo (10,40×2,85 mts.) y que tendría funciones de cuerpo de guardia o cuartel. En el interior del recinto se conservan las plantas de numerosas viviendas, de diferente tipología y seguramente función, y de un aljibe unido a la cara interna del lienzo sur de la muralla. En el exterior se observan restos de una alberca y de un acueducto de mampostería que aún no se han podido relacionar con las estructuras hidráulicas interiores (MALPICA, BARCELÓ, CRESSIER, ROSELLÓ, MARÍN, I 987: pp. 436-446).

Todas las construcciones están hechas en țābiya levantada mediante encofrados sobre una base de piedra que corrige los desniveles de la roca base. A pesar de todo se pueden distinguir en el poblado dos fases constructivas: La primera presenta una țābiya de color gris y textura muy resistente, de un grosor de I,I0 a I,I5 mts. que no alcanza nunca una altura superior a 3 tongadas. Sobre ésta, una țābiya de color más amarillento y menos resistente, de unos 0,80 mts de grosor, que define la segunda fase de construcción (MALPICA, BARCELÓ, CRESSIER, ROSELLÓ, 1986: pp. 285-309).

En el interior podemos distinguir las plantas de numerosas viviendas, todas muy similares excepto las número I bis y 6 , que presentan respectivamente dos y tres naves paralelas cuya función está aún por determinar. El resto de las casas, aún manteniendo rasgos comunes, pueden dividirse claramente en dos grupos:

I.- Corresponde a casas de reducido tamaño (40 $\mathrm{mts}^{2}$. aproximadamente) con dos habitaciones dispuestas en forma de $L$ en torno a un patio, sin subdivisiones internas y sin comunicación entre ellas. 
2.- Un tipo de casa de mayor extensión (70 a $80 \mathrm{mts}^{2}$.), con cuatro o cinco ámbitos dispuestos en forma de $U$ alrededor de un patio (MALPICA, BARCELÓ, CRESSIER, ROSELLÓ, 1986: pp. 295-299).

En cuanto al aljibe, de uso público, éste fue levantado con posterioridad a la cercana casa 9 (MALPICA, BARCELÓ, CRESSIER, ROSELLÓ, MARÍN, I 987: p. 444), y que anula en parte, de la que sólo conservamos dos habitaciones; quizá sea por esta razón por la que no guarde relación con las estructuras hidráulicas presentes en el exterior. Sí presenta, por otra parte, un dato de particular importancia por cuanto en su interior aparecieron monedas tardonazaríes situadas en niveles superficiales; la importancia de este dato reside en que es precisamente en este aljibe $y$ en sus alrededores (la casa 9) donde se localizan gran parte de las cerámicas cristianas que ahora estudiamos.

En el exterior, junto a los restos de la alberca y acueducto de mampostería, se conserva en su ladera Norte y hasta que la pendiente se pierde en el río, el sistema de abancalamiento de tradición islámica, regado por una alberca alimentada en un primer momento por una fuente y posteriormente por una acequia. (BARCELÓ, 1988: pp. 25 I-255).

Estratigráficamente, el Castillejo presenta en principio pocos problemas. Se han podido distinguir solamente dos fases: una primera de abandono y una posterior de destrucción paulatina a lo largo del tiempo (BARCELÓ, CRESSIER, MALPICA, ROSELLÓ,1987: pp. 359374). Esto, junto a la inexistencia de indicios de violencia que propiciaran el abandono y la aparición de múltiples piezas cerámicas in situ, nos hace pensar que éste fuera repentino, en un corto espacio de tiempo, lo suficientemente apresurado como para no permitir a los habitantes volver a recoger sus enseres.

\section{LA CERÁMICA TARDO-NAZARÍ Y CRISTIANA DE EL CASTILLEJO.}

Presentamos a continuación un grupo de cerámicas tardo-nazaríes y cristianas aparecidas en el Castillejo. Como ya hemos apuntado, para el estudio de estos materiales cerámicos no hemos podido apoyarnos en muchas publicaciones de materiales de similares características. Esta escasez bibliográfica aludida afecta a ambas producciones, tanto nazarí (CRESSIER, RIERA, ROSELLÓ, 1992, pp. 5-6) como cristiana, si bien es cierto que no en la misma medida.

En ambos casos la bibliografía que ha tratado estas cerámicas hasta el momento, se ha inclinado más por el estudio de la cerámica de lujo y sus decoraciones que por la cerámica común, grupo en el que se inscribe este lote cerámico. En cerámica nazarí los estudios de que disponemos subrayan la importancia de la decoración?. En cuanto a la cerámica cristiana, ocurre algo similar, sólo que nuestro punto de referencia más cercano hemos de buscarlo en el Levante español; así los estudios de GONZALEZ MARTí (I952); AINAUD LA-SARTE (I952); MARTINEZ CAVIRÓ (1983) y LLUBIÁ (1967), se centran también más en el análisis de las decoraciones cerámicas tales como el azul sobre blanco y la loza dorada. Más cercanos en el tiempo encontramos trabajos que dedican sus páginas a la cerámica de uso común,(AMIGUES, 1986: pp. 27-64; NAVARRO, 1990) o aquéllos que nos ofrecen una tabla tipológica detallada de la cerámica de Paterna aunque ésta sea decorada en verde y manganeso (MARTí, PASCUAL, 1985: pp.716; ibídem, 1986: pp. 525-540)con lo cual la información que sobre esta cerámica poseemos se amplía sobremanera.

\footnotetext{
9 Dentro de este grupo cabe destacar los trabajos de DUDA, Dorothea: Spanich Islamiche Keramik aus Almeria von I2. bis I5. Jarhundert. Deutsches archäologisches institut abteilung Madrid, F.H. Kerle Verlag, Heidelberg, I970; CASAMAR, Manuel: "Notas sobre ajuar cerámico nazari", al-Andalus, XXIV 1969, pp. 189-196; FLORES ESCOBOSA, Isabel:" Estudio preliminar sobre loza azul y dorada nazarí de la Alhambra", Cuadernos de arte y arqueología, 5, Madrid, 1988 pp. 627-635; LLUBIÁ, Luis M: Cerámica medieval española, Labor, Barcelona 1967; ZOZAYA, Juan: "Aperçu général sur la céramique espagnole", I Coloquio Internacional. La Cerámica Medieval del Mediterráno Occidental, Valbonne 1980, pp. 288-29l; FERNÁNDEZ SOTELO, Emilio: Ceuta Medieval. aportación al estudio de sus cerámicas (S. X-XV), 3 Volúmenes, Ceuta, 1988.
} 
En el caso del Castillejo son 15 los fragmentos que podemos adscribir a esta cronología tardo-nazarí y cristiana, una cantidad muy exigua si tenemos en cuenta que en el curso de las actuales investigaciones que se llevan a cabo sobre el Castillejo, son alrededor de 335 las piezas que podemos individualizar del período islámico. El volumen de piezas nos muestra que se trató de una ocupación tardía y de muy corta duración.

\section{Tipología de las piezas.}

Como ya hemos apuntado, presentamos I5 piezas, dentro de las cuales aparecen fragmentos de formas abiertas y cerradas. En particular son II las pertenecientes a formas abiertas ( 5 cazuelas, 4 platos-ataifores y 2 escudillas); las cuatro piezas restantes pertenecen a ejemplares de perfiles cerrados (4 marmitas).

Como se puede observar también son fragmentos que se pueden adscribir a distintas vajillas según la función que ocupen dentro del ajuar doméstico. Así, podemos hablar por un lado de una vajilla de cocina, utilizada para la preparación de alimentos y compuesta por cuatro marmitas y cinco cazuelas, y por otro lado de una vajilla de servicio de mesa destinada a la presentación de las viandas de las que conservamos en este caso cuatro platosataifores y dos escudillas.

Como resultado tenemos, pues, un número pequeño de piezas que, sin embargo, documentan cuatro series cerámicas y dos tipos de vajillas. A pesar de esta diversidad todas las piezas tienen entre sí varias características comunes: en primer lugar se trata de una cerámica de uso común. En ninguno de los casos presentados hallamos las decoraciones cerámicas al uso de la época en que se fabricaron, ya sea azul o blanco, loza dorada o azul-loza dorada, aunque lo cierto es que hasta el momento se conocen pocos fragmentos hallados en esta zona con decoraciones de este $u$ otro tipo fechables en estos momentos.

En segundo lugar, todas ellas fueron recubiertas con un barniz vítreo en su superficie, ya sea para higienizar los alimentos que eran cocinados o consumidos en su interior, o bien para cocinar ciertos platos cuyos ingredientes fueran grasos.

En cualquier caso, las cubiertas vítreas utilizadas tienen como base el plomo, oscilando su coloración entre el blanco y el melado pasando por el verde, en relación a la cantidad de óxido de hierro u óxido de cobre que se utilice en su composición. El color de los vidriados cristianos es muy similar a aquéllos que conservan las cerámicas islámicas del Castillejo. Si bien el blanco es casi inexistente a niveles islámicos en este yacimiento, los melados y el verde son muy parecidos, variando únicamente el tono algo más oscuro de los ejemplares cristianos.

En cuanto a la relación entre la forma y el vidriado, se puede observar una asociación entre ambos elementos: así los vedríos melados suelen recubrir piezas utilizadas para la cocción de alimentos (marmitas, cazuelas). El verde y el blanco por su parte recubren piezas cuya función es la presentación de alimentos, el primer color sobre platos de base plana y el segundo sobre los denominados platos de ala. Las pastas que componen estas piezas son básicamente de dos tipos:

- Unas rojizas, muy compactas y refractarias, con abundante desgrasante de tamaño pequeño y medio.

- Otras de color claro, con menor cantidad de desgrasante, casi inapreciable por su tamaño, y de textura muy porosa.

Como ocurría en el caso de los vidriados, las pastas están asociadas también a determinadas formas; de este modo, las pastas rojizas refractarias se utilizan en las piezas de cocina por tener un contacto directo y continuado con el fuego, mientras que el segundo tipo de pastas son las que componen las piezas utilizadas en el servicio de mesa.

Estos tipos de asociaciones - formas/vidriado o formas/pastas - son habituales en gran parte de los yacimientos bajomedievales, ya sean cristianos (NAVARRO, 1990) o musulma- 
nes, tal y como ocurre en el caso del presente yacimiento en sus niveles de ocupación islámica (CRESSIER, RIERA, ROSELLÓ, 1992); es esta la razón que nos motiva a presentar este estudio mediante unos criterios que aunan elementos tipológicos y funcionales ${ }^{10}$.

\section{Vajilla de cocina.}

MARMITAS (Figura I): Conservamos cuatro fragmentos atribuibles a piezas de esta serie ( $\mathrm{N}^{\circ}$ Inventario: C-85 10.957; C-86 IObis VI 003; C-86 6 II-6I2; C-89 40 I 0-III). Sólo podemos distinguir un tipo que suele encontrarse con frecuencia en los yacimientos de la zona y que nosotros consideramos tardo-nazaríes (MALPICA, GÓMEZ, JIMÉNEZ, 1989: p. 179).

Se trata de una marmita de cuerpo globular con acanaladuras en el hombro, unión cuerpo-cuello resaltado, cuello recto cilíndrico y labio redondeado con resalte en el interior para recibir tapadera. Están acabadas en vedrío melado interior con goterones exteriores y su pasta es compacta y rojiza.

A tenor de sus antecedentes, esta pieza parece ser resultado de la evolución tipológica de la marmita nazarí de cuerpo de tendencia más globular, y cuello igualmente resaltado y cilíndrico aunque de menores dimensiones. Fragmentos que podemos considerar como precedentes se han encontrado en La Rijana (Granada) (MALPICA, GÓMEZ, I99I: pp. 8284), en la atalaya de "El Villar" (Oria, Almería) (DOMÍNGUEZ, MUÑOZ, 1986-87: pp.32-33) en el Cerro del Castillo (Albox, Almería) (MUÑOZ, DOMÍNGUEZ, 1984: pp. 4-8; lám. Ib,c,e.), Níjar (Almería)" e incluso al otro lado del mediterráneo en Belyounech (GRENIER, 1980: pp.238-239; fig. 8 b,c,d), en todos los casos fechadas en los siglos XIV-XV como cerámica nazarí o meriní. También encontramos fragmentos análogos, adscribibles al mismo tipo de marmita en otros tantos yacimientos del antiguo reino nazarí, en Aldeire (Almería) (POZO, RUEDA, 1988-89: pp.20-22; lám. Xa,b), en el cerro del Castillo (Albox, Almería) (MUÑOZ, DOMÍNGUEZ, 1984: pp. 4-8; lám. Ila,b) y en Motril (AA.W., 1990: p. I0I; MALPICA, GÓMEZ, JIMÉNEZ,1989: pp. I76180). Así pues, podemos considerar esta marmita tardo-nazarí como evolución de un tipo de marmita adscribible a un período pleno del emirato, perteneciendo la primera a una etapa final del reino nașrí (Siglo XV), y la segunda a una época anterior (Siglo XIV y parte del XV), aunque no rechazamos que esta forma se mantenga en la primera época cristiana. Si hemos de reseñar, por último, que en ningún caso los fragmentos que encontramos en el Castillejo conservan asas o arranques de ellas, tal y como ocurre en los casos arriba mencionados. Estos fragmentos fueron localizados en distintas zonas del yacimiento (Casas 6, 9, I0; Zona 40).

CAZUELAS (Figura 2): Cinco fragmentos componen esta serie. Podemos distinguir dos tipos:

- El primero, aunque existen diferencias entre algunas piezas ${ }^{12}$ (C-85 I03।IB; C-85 I0235A; C-89 40I6), estaría básicamente definido por un perfil de paredes ligeramente divergentes (no conservamos las bases de las cazuelas) con engrosamiento exterior en el borde, el labio redondeado con, en algunas ocasiones, moldura interior para descanso de tapadera. Por otro lado, la mayoría presenta una serie de incisiones o estrechamientos del labio a modo de pellizco efectuadas antes de la cocción y quizás utilizadas para la expulsión de gases mientras se cocina en ellas; este

\footnotetext{
10 Seguimos aquí la clasificación tipología trazada por GUILLERMO ROSSELLÓ BORDOY en Ensayo de sistematización de la cerámica árabe de Mallorca, Palma de Mallorca, 1978; y funcional establecida por JULIO NAVARRO PALAZÓN para la cerámica islámica en su obra La Cerámica islámica de Murcia, Vol. I, Catálogo, Murcia, 1986.

I I DOMÍNGUEZ BEDMAR, Manuel.; MUÑOZ MARTíN, María del Mar;; RAMOS DÍAZ, José R.: "Tipos cerámicos hispanomusulmanes en Nijar (Almería). I Congreso de Arqueología Medieval Española, Huesca, 1986, pp. 368-369. Lám. 3.; A.A.V.V.: Vivir en al-Andalus. Exposición de cerámica (s. IX-XV), Almería, 1993, pp. 54-55.
}

12 La número 10235 posee algunos rasgos distintivos. 
dato nos confirma su función como vajilla de cocina para elaborar comidas a fuego lento y prolongado, mientras la marmita sería utilizada de distinto modo. Al mismo tiempo, la existencia de la moldura superior del labio junto a las distintas ranuras en el mismo, nos conduce a pensar que estas piezas estaban acompañadas de tapaderas cóncavas del mismo diámetro, tapaderas ya documentadas en época almohade y nazarí, pero mientras en aquel caso están más relacionadas con ataifores, en este caso están claramente relacionadas con este tipo de cazuelas. Desafortunadamente no conservamos ningún fragmento de este tipo de tapadera. Por todos estos datos consideramos esta cazuela de tradición cristiana, de hecho, encontramos cazuelas similares en el Levante (BARRACHINA, CARMONA, MIRALLES, 1984: p. 4II) en época cristiana, al tiempo que son frecuentes en los niveles cristianos del XVI de yacimientos cercanos (AA.VV., 1990: pp. 103104). Por el contrario, las relaciones con cazuelas nazaríes no están del todo claras. Los dos primeros fragmentos aparecen en la casa 9 y el último en la zona 40.

-El segundo tipo, se trata de una cazuela ligeramente convexa, paredes divergentes y borde en alero, cubiertas por un barniz melado en el interior y goterones exteriores, su pasta es rojiza. No conocemos piezas similares de época nazarí tanto en los niveles musulmanes del Castillejo como en otros yacimientos, debido a su menor diámetro, aunque parecen guardar relaciones tipológicas con las cazuelas de borde en alero de tradición almohade-nazarí. Por otro lado, encontramos perfiles similares en yacimientos cristianos del Levante aunque pertenecientes a la serie plato. Estas piezas aparecen en el Castillo de la Mola (NAVARRO, 1990: lám. LXVI, n० |36I) y en el Teatro romano de Zaragoza (PALOMAR, 1986: p. 509), decoradas con azul y reflejos metálicos.

Sólo conservamos dos fragmentos hallados, uno en el aljibe (965) y otro en la cercana casa 9 (9-II-062), que, a falta de ejemplares análogos en época nazarí y su lugar de aparición, hemos de considerar cristianas.

\section{Vajilla de mesa.}

PLATO (Figura 3): Con un total de cuatro piezas podemos distinguir dos tipos:

-Tipo A: Son los llamados platos de ala (806-003 ।I, 965). Aparecieron en el interior del aljibe, y ambos ejemplares tienen un perfil similar (base cóncava, cuerpo de paredes divergentes, pestaña superior horizontal que se acompaña en el interior por una quebradura, y labio redondeado) junto a una misma cubierta vítrea blanca. Se trata de los ejemplares más claramente cristianos, no guardan ninguna relación tipológica con el resto de los materiales del Castillejo de época islámica, además de que los ejemplares que han sido fechados como nazaríes con características similares pertenecen a series de lujo decoradas conservadas en el museo Hispano-musulmán de la Alhambra' ${ }^{13}$, que pudieran estar influidos por ejemplares cristianos contemporáneos. Sí existen numerosas analogías con piezas de otros lugares en época cristiana tanto en el Levante como en yacimientos más cercanos, mostrando con ello el nivel de su extensión ${ }^{14}$.

\footnotetext{
13 CASAMAR, Manuel.: Notas sobre cerámica..., pp. 193-194., Figs. 5-7; FLORES ESCOBOSA, Isabel.: "Estudio del material arqueológico del Museo Nacional de Arte Hispanomusulmán de Granada: la loza azul y dorada". Anuario Arqueológico de Andalucía, t. II, 1989, p. 4II. Lám. 3; RUIZ GARCÍA, Alfonso.: La cerámica doméstica nazarí en vidriado verde del Museo Hispano-musulmán, Tesina inédita mecanografiada para la Universidad de Granada, Granada, 1980, p. 19, Lám. II. Lo clasifica como ataifor tipo F.

I4 REDMAN, Charles.: "Late medieval ceramics from Qsar-es-Seghir". I Coloquio Internacional Cerámica Medieval en el Mediterráneo Occidental, Valbonne, 1980, p. 255.; TURINA GÓMEZ, Araceli.: "Cerámicas medievales cristianas de Alcalá de Henares”, I Congreso de Arqueología Medieval Española, Huesca, 1986, p. 655.; NAVARRO POVEDA, Concepción: Excavaciones arqueológicas en el Castillo..., p. 2I5.; MARTÍ, Javier; PASCUAL, Josefa: La cerámica verde y manganeso..., p. I4.; PASCUAL, Josefa; MARTÍ, Xavier.: “Importaciones cerámicas valencianas en el castell Formos de Balaguer", I Congreso de Arqueología Medieval Española, Huesca, 1986, pp. 637-647. Figs. 5,6,7.; MALPICA CUELLO, Antonio; GÓMEZ BECERRA, Antonio; JIMÉNEZ LOZANO, Esperanza: Informe de la excavación..., p. 159.; A.A.V.V.: De Paterna a Mutrāyil... pp. 108.
} 
-Tipo B: Se caracteriza por tener la base plana y paredes divergentes. De las dos piezas que poseemos, una de ellas conserva una quebradura en su cuerpo similar a la de los ataifores musulmanes bajomedievales (C-87.0026) y vidriado en verde. El otro, del que sólo conservamos un fragmento, no presenta esta quebradura y sus paredes son rectas y divergentes (C85.3066). Conservamos fragmentos análogos en el material vidriado en verde del museo Hispano-musulmán de la Alhambra ${ }^{15}$ que nos permiten fecharlo en el siglo XV.

ESCUDILLA (Figura 4): Sólo conservamos dos fragmentos adscribibles a esta serie, ambos de diferente tipo:

- C-85. I 0324. No conservamos la base de esta pieza. Las paredes del cuerpo son divergentes aunque se aprecia una ligera carena interior en la parte central de las mismas. Su perfil es similar a muchos de los aparecidos en yacimientos del Levante, pues su uso parece estaba muy extendido en época cristiana ${ }^{16}$.

- C-86.9|8-00।. Se trata de dos fragmentos, seguramente de una misma pieza. Posee repié anular y sus paredes son curvas y divergentes. Vidriado en verde claro, sus antecedentes arrancan de la cerámica nazarí más tardía; conocemos piezas con una tipología similar datadas como nazaríes en la Alhambra' ${ }^{17}$, aunque parece clara su presencia en época cristiana.

\section{CONCLUSIONES}

Presentamos en este artículo un material determinado del Castillejo; este vendría justificado por su clara diferenciación del resto del conjunto cerámico del yacimiento y que ha sido publicado en parte (CRESSIER,
RIERA, ROSELLÓ,1992). Se trata de una cerámica procedente de un momento distinto al del abandono general del yacimiento (Siglo XIV); esta cerámica nos documenta una reocupación posterior del mismo, más exactamente varias reocupaciones temporales intermitentes. Una o más de ellas hemos de localizarlas en la época final del reino nazarí, fines del siglo $\mathrm{XV}$; de este momento son las cerámicas que hemos considerado tardo-nazaríes. Esta reocupación hubo de ser en un período muy corto de tiempo y se realizó de forma salpicada en casi la totalidad occidental del yacimiento, es decir, las casas situadas en el sector o. del yacimiento que debieron mantenerse en pie (no sabemos por el momento en qué condiciones) y pudieron ser utilizadas mientras los campos próximos seguían cultivados por los habitantes de las alquerías cercanas. En ella reconocemos las marmitas de cuello cilíndrico y resaltado y los ataifores del tipo $B$ hallados en el baluarte defensivo (Sondeo 3 del año 1985), casa 00, casa 9, casa I0bis, casa 6, y Zona 40.

Al mismo tiempo encontramos en este conjunto de cerámicas un grupo que hemos de considerar netamente cristianas, y por lo tanto perteneciente a una reocupación posterior a la conquista de estas tierras por los castellanos. A ella debemos la existencia en el Castillejo de platos en ala, cazuelas de borde moldurado y escudillas. Resulta en todo caso curioso que esta cerámica cristiana sólo aparezca en los niveles superficiales del aljibe y la cercana casa 9 , la única que a tenor de estos datos debió quedar habitable entre una reocupación y otra. No sabemos cuáles fueron la causas de la destrucción del Castillejo, pero todo nos indica que desde el momento de abandono, el proceso de desplome de estructuras fue gradual, primero de la zona oriental y posteriormente de la occi-

\footnotetext{
15 RUIZ, 1980: p. 18, Lám. II. Ataifor Tipo Da.

16 MARTí, PASCUAL, 1986: pp. 526-540;; MESQUIDA GARCÍA, M.; AMIGUES, F., (1986): "Hallazgo de un "pozo" de cerámica en el casco antiguo de Paterna", I Congreso de Arqueología Medieval Española, Huesca, p. 556. BARRACHINA, CARMONA, MIRALLES, 1984: p. 415.; NAVARRO, 1990; CARDONA ESCRIVÁ, J.; MARTí OLTRA, X., (1986): "Materiales bajomedievales del Hospital de Sant Marc. Gandía (Valencia)" I Congreso de Arqueología Medieval Española, Huesca. p. 606

17 FLORES, 1989: pp. 409-4I I. Láms. I,2,3,4; RUIZ, 1980: p. 20-22.; La jofaina tipo C es la que guarda más relación con esta pieza:; MUÑOZ, DOMÍNGUEZ, 1984: pp. 24-26. Lám. XII.
} 
dental, restando en pie sólo el aljibe por ser el elemento más robusto y estar adosado directamente a la muralla.

Quedan aún por aclarar, también, las causas de la reocupación cristiana cuando el Castillejo estaba prácticamente en ruinas. Creemos que este lugar pudo ser utilizado como refugio de los moriscos a lo largo de la cruenta lucha que mantuvieron con el estado castellano en la segunda mitad del XVI tal y como nos informa Luis del Mármol Carvajal, aunque éste sólo mencione el Cerro del Fuerte (MÁRMOL, 1946: pp. 246-247).

En todo caso, nos encontramos con dos producciones cerámicas muy distintas entre sí: aunque la tardo-nazarí recoge algunas influencias de la castellana contemporánea, en el caso de la producción castellana, nos aparecen tipologías totalmente nuevas hasta el momento. No hemos de olvidar que las piezas que conservamos del Castillejo pertenecen a una vajilla de uso común. En el caso de las cerámicas de lujo, éstas eran más receptivas a la influencias exteriores de otras culturas o incluso a la importación de materiales. Un cambio ceramológico en producciones de lujo nos confirmarían bien una influencia o bien un cambio de gustos en las capas altas de la sociedad que demandaba este tipo de producciones. En esta ocasión, la cerámica es de uso común y utilizada por las capas más bajas de la sociedad; si en este caso documentamos un importante cambio hemos de pensar que éste estuvo motivado por una notable modificación de las estructuras socio-económicas motivadas por la conquista castellana. Modificaciones que debieron afectar a la totalidad de los estratos sociales (MALPICA, 1987: pp. 389-390; 1989: pp. |8।-186.)

\section{BIBLIOGRAFÍA}

A.A.V.V. (1990): De Paterna a Mutrāyil. Historia, Arqueología y Paisaje, Motril.

A.A.V.V. (1993): Vivir en al-Andalus. Exposición de cerámica (s.IX-XV), Almería.

AINAUD LASARTE, J. (1952): "Cerámica y vidrio" en Ars Hispaniae, X, Madrid.
AMIGUES, F. (1986): "Premieres approches de la céramique commune des ateliers de Paterna (Valencia) L"'obra aspra" XIV-XV", Mélanges de la Casa Velazquez, XXII.

BARCELÓ, M. (1988): "La arqueología extensiva y el estudio de la creación del espacio rural", en Arqueología medieval. En las afueras del "Medievalismo", Barcelona.

BARCELÓ, M.; CRESSIER, P.; MALPICA, A.; ROSSELLÓBORDOY, G. (1987): "Investigaciones en "El Castillejo" (Los Guájares, Granada)", V Jomades d'Estudis Històrics Locals, Palma de Mallorca.

BARRACHINA, A; CARMONA, P; MIRALLES, J. (1984): "Excavaciones en el Molí del Testar de Patema (Valencia)". Al-Qanțara, V.

CARDONA ESCRIVÁ, J:; MARTÍ OLTRA, X. (1986): "Materiales bajomedievales del Hospital de Sant Marc. Gandía (Valencia)". I Congreso de Arqueología Medieval Española, Huesca, pp. 595-612.

CASAMAR, M. (1969): "Notas sobre cerámica del ajuar nazari", al-Andalus, XXIV.

CRESSIER, P.; MALPICA CUELLO, A; ROSELLÓ BORDOY, G. (1987): "Análisis del poblamiento medieval de la Costa de Granada: el yacimiento de "El Castillejo" y el valle del río de la Toba (Los Guájares)". II Congreso de Arqueología Medieval Española, Tomo III, Madrid.

CRESSIER, P.; RIERA FRAU, M.; ROSELLÓ BORDOY, G (1992): "La cerámica tardo-almohade y los orígenes de la cerámica Nasri", Quadems de Ca la gran cristiana, XI.

DOMÍNGUEZ BEDMAR, M.; MUÑOZ MARTíN, Ma del M.; RAMOS DÍAZ, J. R. (1986): "Tipos cerámicos hispanomusulmanes en Níar (Almería). I Congreso de Arqueología Medieval Española, Huesca.

DOMÍNGUEZ BEDMAR, M.; MUÑOZ MARTíN, Ma del M. (1986-87): "Materiales cerámicos islámicos de la atalaya de El Villar. (Oria, Almería)". Roel. 7-8.

DUDA, D. (1970): Spanisch-Islamische Keramik aus Almería vom 12. bis 15. Jarhundert. Deutsches archäologisches institut abteilung Madrid, F.H. Kerle Verlag, Heidelberg.

FERNÁNDEZ SOTELO, E. (1988): Ceuta Medieval. Aportación al estudio de sus cerámicas (S. X-XV), 3 Volúmenes, Ceuta.

FLORES ESCOBOSA, I. (1989): "Estudio del material arqueológico del Museo Nacional de Arte Hispanomusulmán de Granada: la loza azul y dorada". Anuario Arqueológico de Andalucía, t. II.

FLORES ESCOBOSA, I. (1988): "Estudio preliminar sobre loza azul y dorada nazarí de la Alhambra", Cuademos de arte y arqueología, 5, Madrid.

GONZÁLEZ MARTí, M. (1952): Cerámica del Levante español. Siglos medievales, Tomo I, Barcelona.

GRENIER DE CARDENAL, M. (I980): "Recherches sur la céramique médiéval marocaine". I Coloquio Internacional La Cerámica Medieval del Mediterráneo Occidental. Valbonne. 
LLUBIÁ, L. M. (1967): Cerámica medieval española, Labor, Barcelona.

MALPICA CUELLO, A. (1986): "Castillos y sistemas defensivos en las tahas alpujarreñas de Sāḥyl y Suḥayl: un análisis histórico y arqueológico". I Congreso de Arqueología Medieval Española, Huesca.

MALPICA CUELLO, A. (199|): "Medio natural y paisajes rurales en Sierra Lújar a finales de la Edad Media", Revista del Centro de Estudios Históricos de Granada y su Reino., Granada, pp. 7I-88.

MALPICA CUELLO, A. (1987): "Poblamiento del Reino de Granada: Estructuras nazaríes y modificaciones castellanas". $\checkmark$ Jomades d'Estudis Històrics Locals. Palma de Mallorca, pp. 389-390.

MALPICA CUELLO, A. (1989): "Estructura de poblamiento de la Costa de Granada a fines de la Edad Media", Studia Histórica, pp. 157-186

MALPICA CUELLO, A. (1990): "Salobreña de la época medieval a la moderna", Ciclo de conferencias pronunciadas con motivo del $V$ centenario de la incorporación de Salobreña a la Corona de Castilla (1489-1989), Salobreña.

MALPICA CUELLO, A.; BARCELÓ, M.; CRESSIER, P.; ROSSELLÓ BORDOY, G. (1986): "La vivienda rural musulmana en Andalucía Oriental: el hábitat fortificado de "El Castillejo" (Los Guájares, provincia de Granada). Congreso de Arqueología Espacial, X, Teruel, 1986.

MALPICA CUELLO, A.; BARCELÓ I PERELLÓ, M.; CRESSIER, P.; ROSELLÓ BORDOY, G.; MARÍN DÍAZ, N. (1987):

"Excavación de El Castillejo (Los Guájares, Granada), 1985", Anuario Arqueológico de Andalucía, T.ll, Sevilla.

MALPICA CUELLO, A.; GÓMEZ BECERRA, A. (1991): Una cala que llaman La Rijana. Arqueología y paisaje. Granada.

MALPICA CUELLO, A.; GÓMEZ BECERRA, A.; JIMÉNEZ LOZANO, E. (1989): "Informe de la excavación de urgencia realizada en el solar de la Plaza de España (Motril, provincia de Granada)". Anuario Arqueológico de Andalucía, t. I.

MALPICA CUELLO, A.; RODRÍGUEZ LOZANO, J. A. (1982): "La alquería de Cázulas y la tierra de Almuñécar a finales del siglo XV. Notas y documentos para su estudio". Estudios de Historia y Arqueología Medievales, II. pp.7 I-89.
MÁRMOL CARVAJAL, L. del. (1946): Historia de la rebelión y castigo de los moriscos del reino de Granada, Edic. B.A.E., t. XXI, Madrid.

MARTÍ, X.; PASCUAL, J. (1985): "La cerámica verde y manganeso de Paterna. Propuesta de método para su estudio (avance preliminar)". Archeología Medievale, XIII.

MARTÍ, X:; PASCUAL, J. (1986): "Propuesta de seriación de la cerámica verde-manganeso valenciana". I Congreso de Arqueología Medieval Española, Huesca.

MARTINEZ CAVIRÓ, B. (1983): La loza dorada, Madrid.

MESQUIDA GARCÍA, M.; AMIGUES, F. (1986): "Hallazgo de un "pozo" de cerámica en el casco antiguo de Paterna", I Congreso de Arqueología Medieval Española, Huesca.

MUÑOZ MARTíN, Ma del M.; DOMÍNGUEZ BEDMAR, M. (1984): "Cerámica hispano-musulmana del cerro del Castillo (Albox, Almería)". Roel, 5.

NAVARRO POVEDA, C. (1990): Excavaciones arqueológjcas en el Castillo de la Mola (Novelda-Alicante). II. Las cerámicas comunes (siglos XIV-XV), Alicante.

PALOMAR LLORENTE, Mª E. (1986): "La cerámica medieval de los siglos XIII-XV en el Teatro romano de Zaragoza". I Congreso de Arqueología Medieval Española, Huesca.

PASCUAL, J:; MARTÍ, X. (1986): "Importaciones cerámicas valencianas en el castell Formos de Balaguer", I Congreso de Arqueología Medieval Española, Huesca, 1986,

POZO MARTÍN, R; RUEDA CRUZ, I. (1988-89): "Aldeire: Una alquería de Tíjola (Almería)", Roel, 9-I0.

REDMAN, Ch. (1980): "Late medieval ceramics from Qsares-Seghir". I Coloquio Intemacional Cerámica Medieval en el Mediterráneo Occidental, Valbonne.

RUIZ GARCÍA, A. (1980): La cerámica doméstica nazani en vidriado verde del Museo Hispano-musulmán, Tesina inédita mecanografiada para la Universidad de Granada, Granada.

TURINA GÓMEZ, A. (1986): "Cerámicas medievales cristianas de Alcalá de Henares", I Congreso de Arqueología Medieval Española, Huesca.

ZOZAYA, J. (1980): " Aperçu général sur la céramique espagnole", I Coloquio Internacional la Cerámica Medieval del Mediterráneo Occidental, Valbonne. 


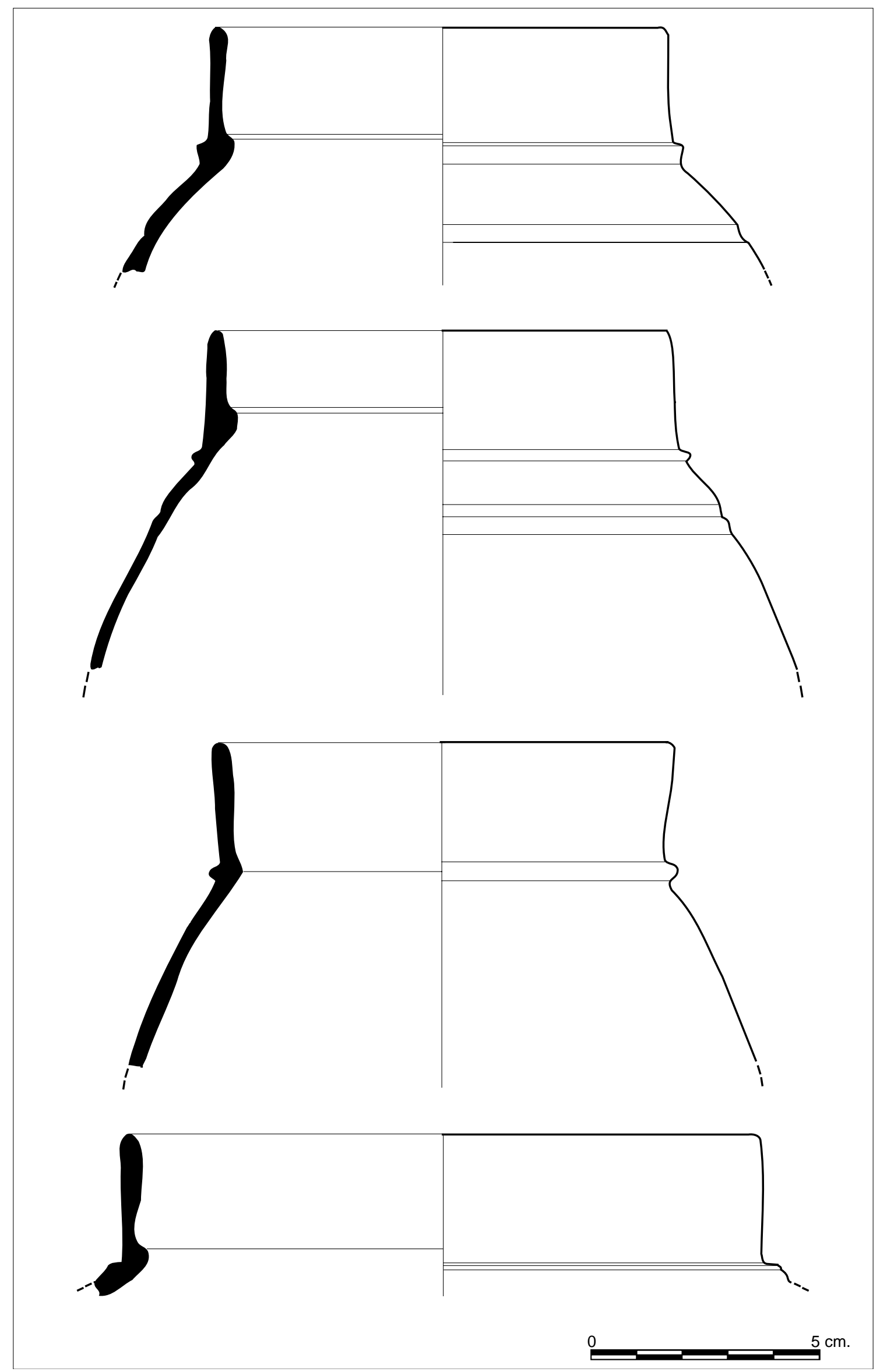

Fig. I. Marmitas 


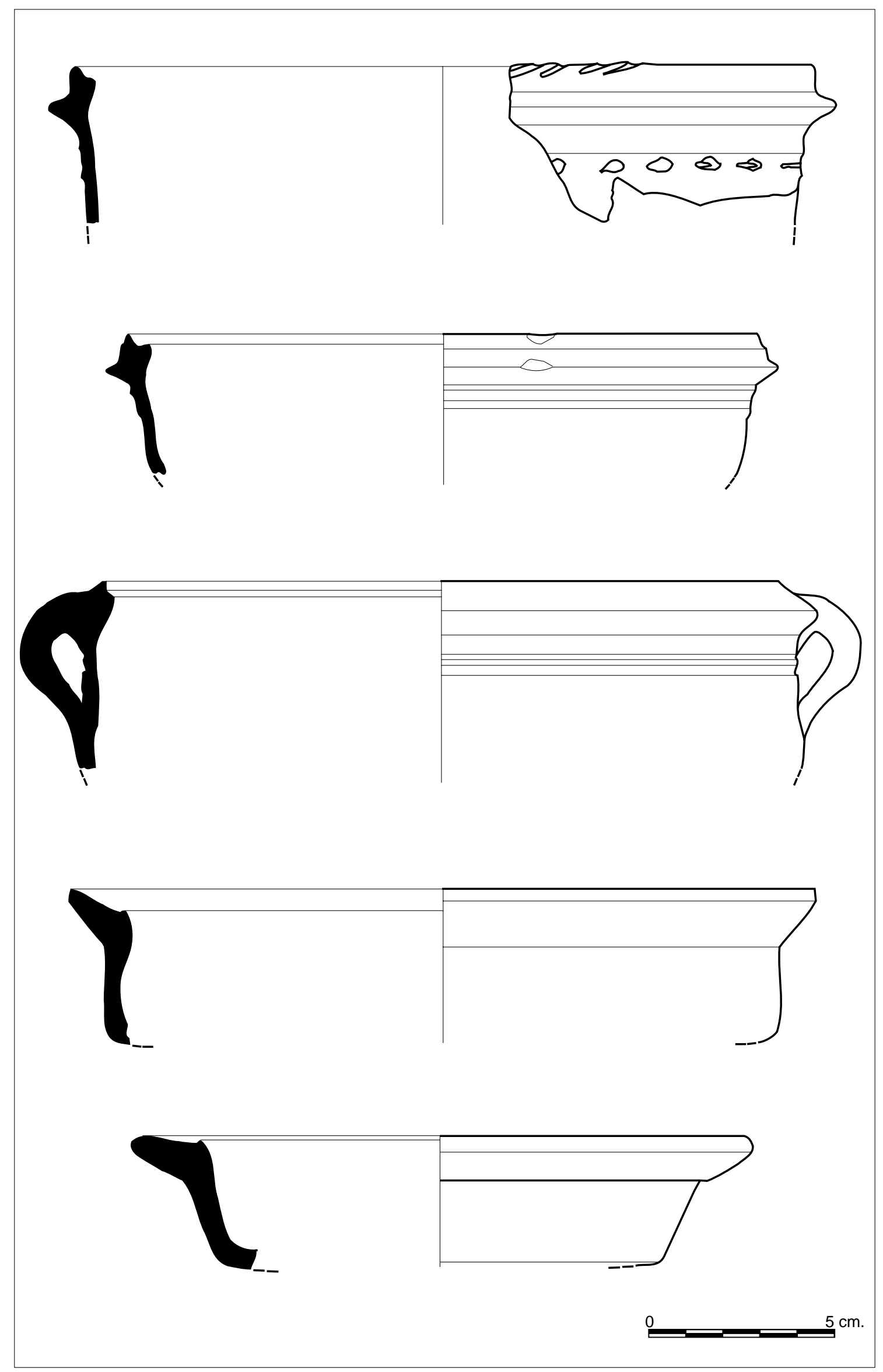

Fig. 2. Cazuelas 


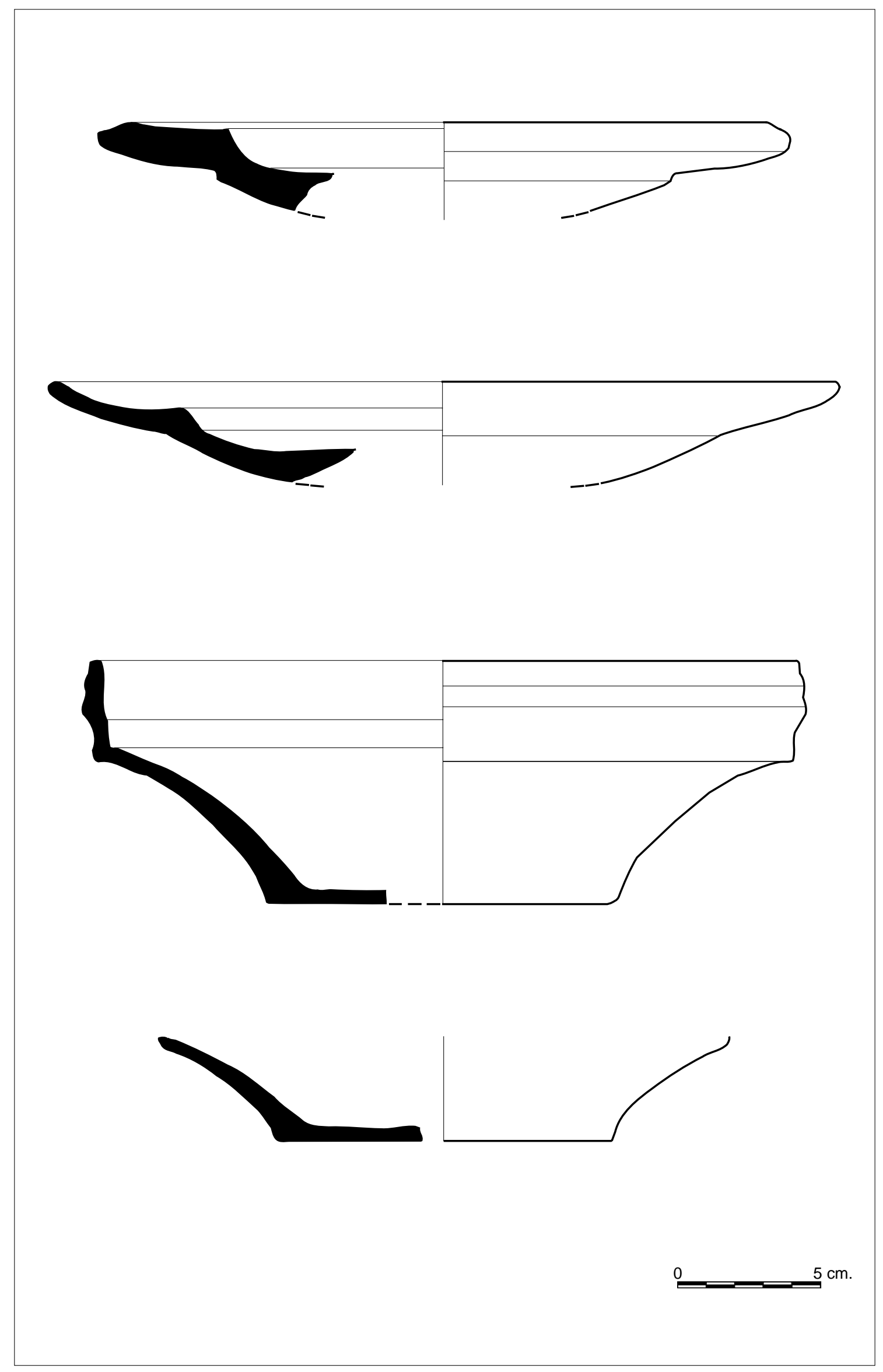

Fig. 3. Platos 


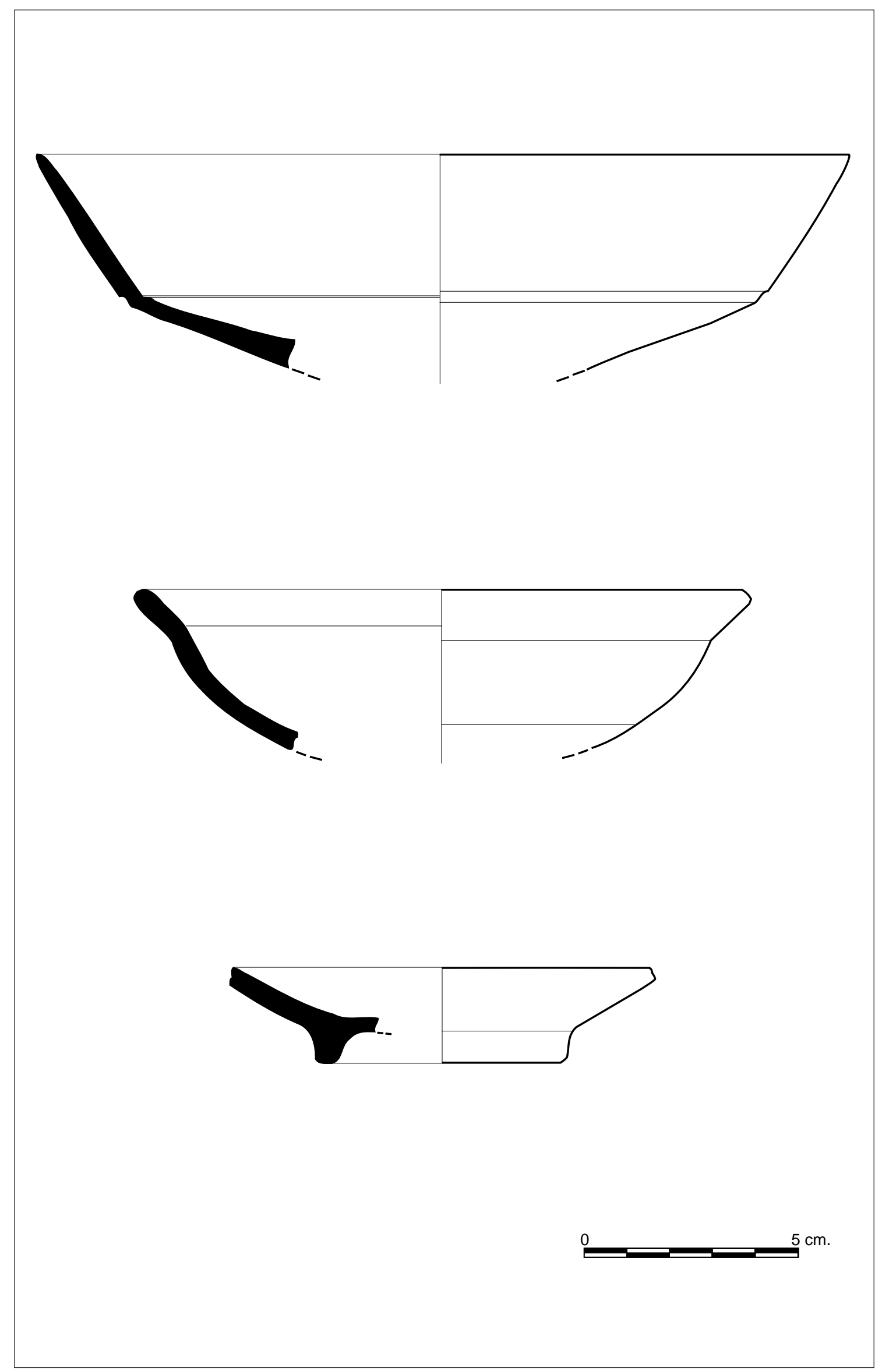

Fig. 4. Escudillas 